\title{
Microstructures and Hardness of Mo Heater Chip Brazed with Au-18 mass\% Ni
}

\author{
Ikuo Shohji ${ }^{1}$, Yoshinori Kawabata ${ }^{1}$ and Yoshitaka Kimura ${ }^{2}$ \\ ${ }^{1}$ Faculty of Engineering, Gunma University, Kiryu 376-8515, Japan \\ ${ }^{2}$ Apollo Giken Co., Ltd., Sawa-gun Azuma 379-2223, Japan
}

Microstructures and hardness of Mo heater chips brazed with Au-18 mass\%Ni were investigated. The reaction layer of Mo-Ni compounds forms at the brazed interface. Spherical MoNi compounds form initially, and they change columnar ones with increasing brazing time. The reaction layer grows abruptly when the brazing time is more than 5 minutes with the brazing temperature range from $930^{\circ} \mathrm{C}$ to $970^{\circ} \mathrm{C}$. The Vickers hardness of MoNi is evaluated as $682 \mathrm{Hv}$. That is approximately three and four times those of Mo and the Au-18Ni filler, respectively.

(Received November 22, 2002; Accepted February 5, 2003)

Keywords: molybdenum, gold-18Nickel, brazing, interfacial reaction, Vickers hardness, microstructure

\section{Introduction}

Coil components are used in many electronic devices. ${ }^{1,2)}$ They are composed of ceramic substrates and $\mathrm{Cu}$ wires coated with thin organic materials. Usually, $\mathrm{Cu}$ wires are bonded on solder-coated pads on the ceramic substrate by a thermocompression bonding method in which Mo heater chips are used. A thermocouple is attached to the surface of the Mo heater chip by resistance welding to control the bonding temperature. Since it is difficult to weld the thermocouple directly onto the surface of the Mo chip, a thin Ni sheet is bonded onto the surface of Mo by a diffusion bonding method. This diffusion bonding method requires a vacuum environment, thermocompression conditions and relatively long bonding time (approximately 1 hour).

In this study, a brazing method using Au-18 mass\%Ni paste was investigated as a new surface treatment method for Mo in order to weld a thermocouple onto the surface of a Mo chip. The brazing method using $\mathrm{Au}-18 \mathrm{Ni}$ paste does not require thermocompression, which makes it possible to conduct the surface treatment of the Mo chip in a shorter bonding time than by the conventional diffusion bonding method. It may become a low-cost process for the surface treatment of Mo.

The aim of this study is to examine the microstructures and hardness of the $\mathrm{Mo} / \mathrm{Au}-18 \mathrm{Ni}$ brazed interface in order to evaluate the optimal brazing conditions.

\section{Experimental Procedure}

Figure 1 shows the geometry and dimensions of the Mo heater chip used in this study. Usually, the thermocouple is bonded onto the surface of the chip edge of which the width is $2 \mathrm{~mm}$. Thus, a similar area of the Mo heater chip was used in this study. Filler paste of $\mathrm{Au}-18 \mathrm{Ni}$ was also prepared as a compound with $\mathrm{Au}-18 \mathrm{Ni}$ powder and an organic binder. The compound ratio of $\mathrm{Au}-18 \mathrm{Ni}$ powder to the binder was $4: 1$ (mass\%).

Five $\mathrm{mg}$ of $\mathrm{Au}-18 \mathrm{Ni}$ paste was applied to the surface of the Mo chip. Brazing was carried out using an infrared gold image furnace in a vacuum of $4 \times 10^{-2} \mathrm{~Pa}$. Brazing was performed at three temperatures of $930^{\circ} \mathrm{C}, 950^{\circ} \mathrm{C}$ and $970^{\circ} \mathrm{C}$ for brazing times ranging from 1 to $30 \mathrm{~min}$. In the brazing

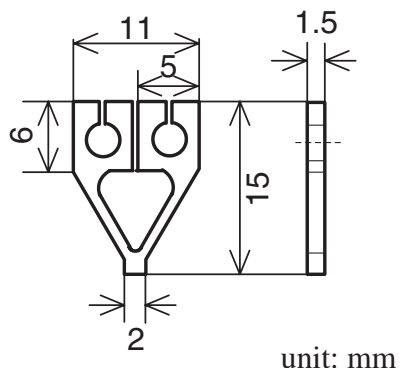

Fig. 1 Geometry and dimensions of Mo heater chip.

process, the specimen was heated from room temperature (R.T.) to each brazing temperature in $10 \mathrm{~min}$ and held at that temperature for a certain time. Then, the specimen was cooled from the brazing temperature to $350^{\circ} \mathrm{C}$ in $10 \mathrm{~min}$ and subsequently allowed to cool naturally.

To investigate microstructures of the $\mathrm{Mo} / \mathrm{Au}-18 \mathrm{Ni}$ brazed interfaces, the cross sections of the specimens were observed with an optical microscope (OM), a scanning electron microscope (SEM) and an electron probe X-ray microanalyzer (EPMA). The Vickers hardness of microstructures in the $\mathrm{Mo} / \mathrm{Au}-18 \mathrm{Ni}$ interfaces was also evaluated. A load of $0.245 \mathrm{~N}$ or $0.98 \mathrm{~N}$ was applied to each microstructure for $10 \mathrm{~s}$ during the Vickers hardness measurement.

\section{Results and Discussion}

\subsection{Microstructures of Mo/Au-18Ni interfaces}

Figure 2 shows microstructures of $\mathrm{Mo} / \mathrm{Au}-18 \mathrm{Ni}$ interfaces after brazing at $950^{\circ} \mathrm{C}$. Reaction layers are observed at the interfaces in all specimens. In the case of the brazing time of $1 \mathrm{~min}$, the thickness of the reaction layer is approximately $16 \mu \mathrm{m}$. This layer consists of spherical phases with a diameter of approximately $5 \mu \mathrm{m}$. Similar phases are also observed in the $\mathrm{Au}-18 \mathrm{Ni}$ filler layer. In the case of specimens brazed at $950^{\circ} \mathrm{C}$ for more than $5 \mathrm{~min}$, most phases in the reaction layer change from a spherical shape to a columnar shape. The thickness of the reaction layer is saturated at approximately $30 \mu \mathrm{m}$. Moreover, a lamellar structure is observed in the Mo layer adjacent to the brazed interface.

Figures 3 and 4 show results of EMPA analysis for the microstructures shown in Figs. 2(a) and (d), respectively. Mo 


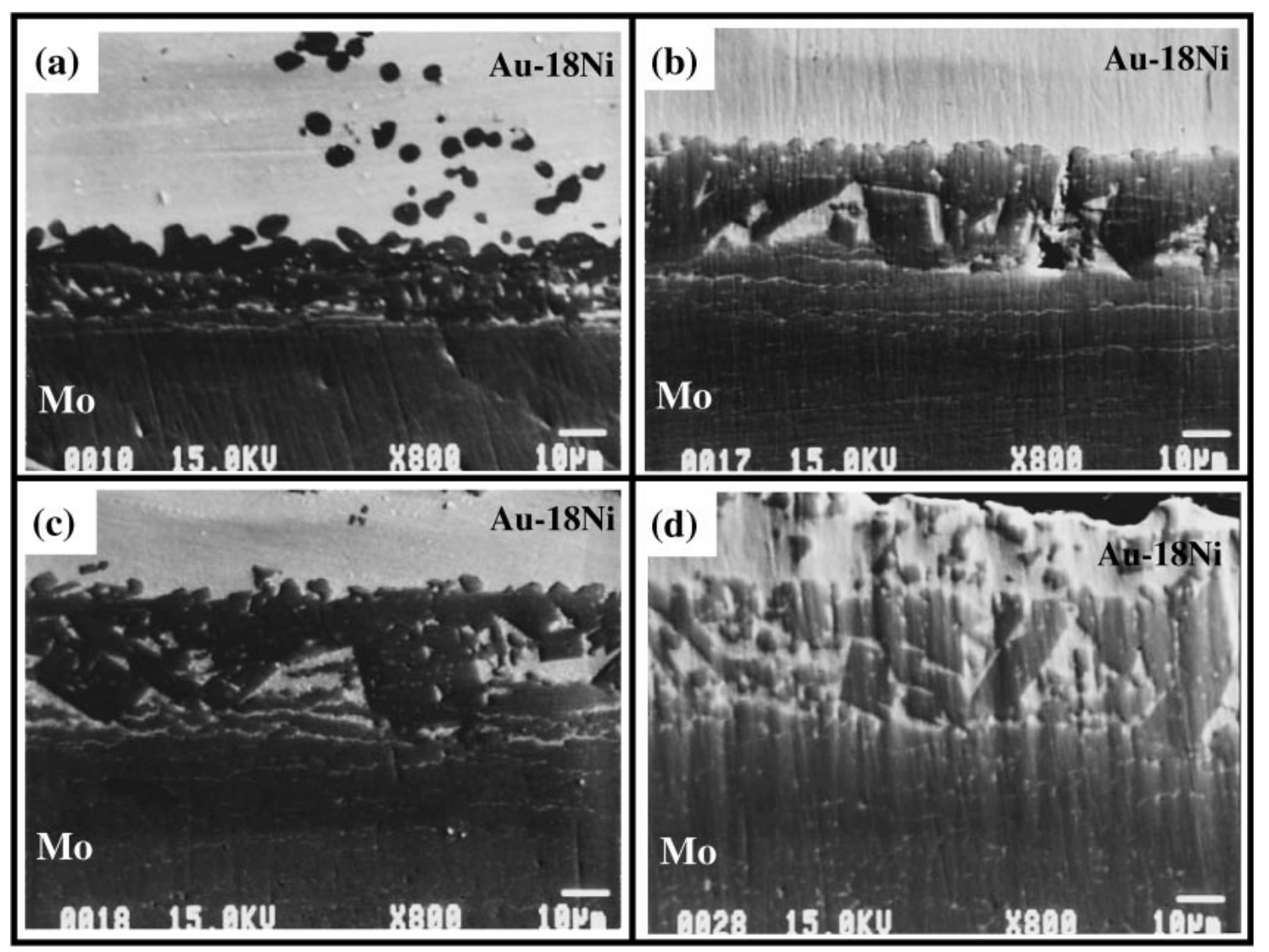

Fig. 2 Microstructures of $\mathrm{Mo} / \mathrm{Au}-18 \mathrm{Ni}$ interfaces brazed at $950^{\circ} \mathrm{C}$ for $1 \mathrm{~min}$. (a), $5 \mathrm{~min}$. (b), $10 \mathrm{~min}$. (c) and $30 \mathrm{~min}$. (d), respectively.

and $\mathrm{Ni}$ are detected in the reaction phases in the interfaces (dark gray areas). Moreover, those phases are identified as Mo-Ni compounds with a composition of approximately $\mathrm{Mo}: \mathrm{Ni}=1: 1$ and which contain a few at\% $\mathrm{Au}$, as determined by the quantitative analysis. Therefore, this compound is inferred to be MoNi using the Mo-Ni phase diagram $^{3)}$ shown in Fig. 5.

$\mathrm{Au}$ is detected in the bright gray area in the lamellar microstructure in the Mo layer adjacent to the brazed interface. In brazing, $\mathrm{Ni}$ and $\mathrm{Au}$ atoms diffuse into Mo. $\mathrm{Ni}$ atoms react with $\mathrm{Mo}$ and $\mathrm{MoNi}$ phases form at the brazed interface. Since Au and Mo follow the eutectic-type phase diagram, ${ }^{4)}$ no compounds form at the brazed interface and a phase of $\mathrm{Au}$ and Mo laminations forms in the Mo layer in the vicinity of the brazed interface. Similar microstructures are observed in specimens brazed at $970^{\circ} \mathrm{C}$. In the case of brazing at $930^{\circ} \mathrm{C}$, similar microstructures are observed in most of the interfaces, but nonmelted fillers are also observed in some parts of the filler layer. Therefore, the brazing temperature must be controlled to be above $950^{\circ} \mathrm{C}$.

\subsection{Growth of reaction layer at the brazed interface}

Figure 6 shows the relationship between the thickness of the reaction layer and the brazing time. With increasing brazing time, the thickness of the reaction layer increases at all temperatures investigated. In particular, the thickness of the reaction layer abruptly increases at the brazing time of $5 \mathrm{~min}$, and subsequently, the growth of the reaction layer becomes gradual. The effect of the brazing temperature on the growth rate of the reaction layer is negligible in the temperature range from 930 to $970^{\circ} \mathrm{C}$.

Figure 7 shows the relationship between the thickness of the filler layer and the brazing time. The thickness of the filler layer decreases with increasing brazing time. As shown in Fig. 6, the reaction layer grows with increasing brazing time. Moreover, the wettable area also expands with increasing brazing time because the wettability of the paste generally improves with increasing temperature. Therefore, the thickness of the filler layer decreases due to the effects of both the growth of the reaction layer and the expansion of the wettable area. In this study, it was difficult to control the initial area in which the filler was applied because the paste filler was used. The area in which the paste filler is applied is scattered, and thus, the wettable area is also scattered. The thickness of the filler layer is strongly dependent on the extent of the wettable area. Therefore, the data in Fig. 7 are more scattered than the data of the thickness of the reaction layer shown in Fig. 6. Although the data are relatively scattered, the effect of the brazing temperature on the change of the filler thickness is also negligible, as in the case of the reaction layer.

In the conventional method, in which a $\mathrm{Ni}$ sheet is bonded onto the Mo chip by diffusion bonding, the Ni sheet with a thickness of $100 \mu \mathrm{m}$ is used. Since the reaction layer formed by diffusion bonding is at most a few $\mu \mathrm{m}$, the thickness of the Ni layer is also approximately $100 \mu \mathrm{m}$ after bonding. Thus, a similar thickness is required for the filler layer in order to apply the method investigated in this study. From this viewpoint, the suitable brazing time is defined as a few minutes at each temperature. 


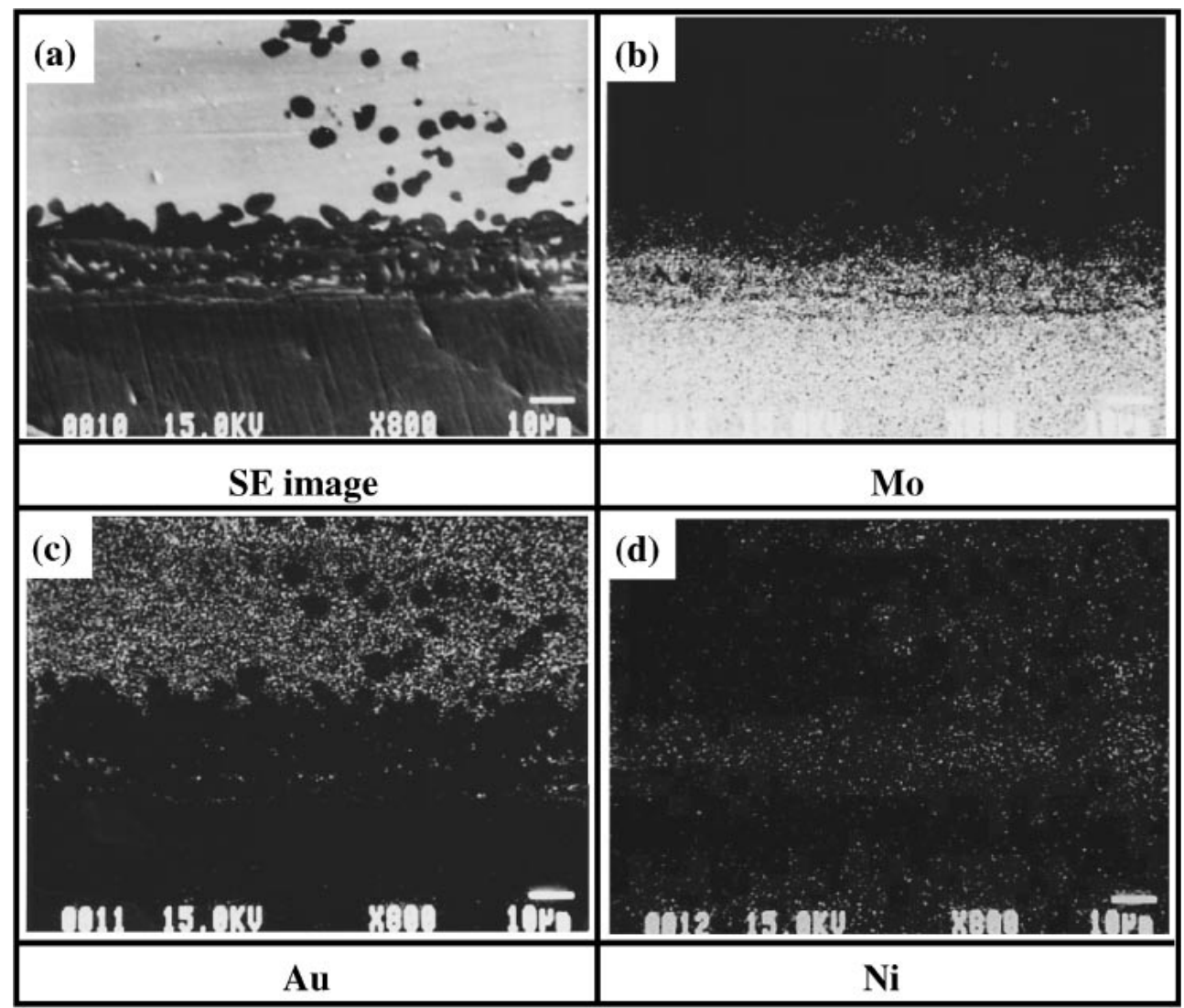

Fig. 3 EPMA plane analysis results of the cross section of Mo/Au-18Ni interface brazed at $950^{\circ} \mathrm{C}$ for $1 \mathrm{~min}$.; $\mathrm{SE}$ image (a) and Mo (b), $\mathrm{Au}(\mathrm{c})$ and $\mathrm{Ni}(\mathrm{d})$ images of (a).

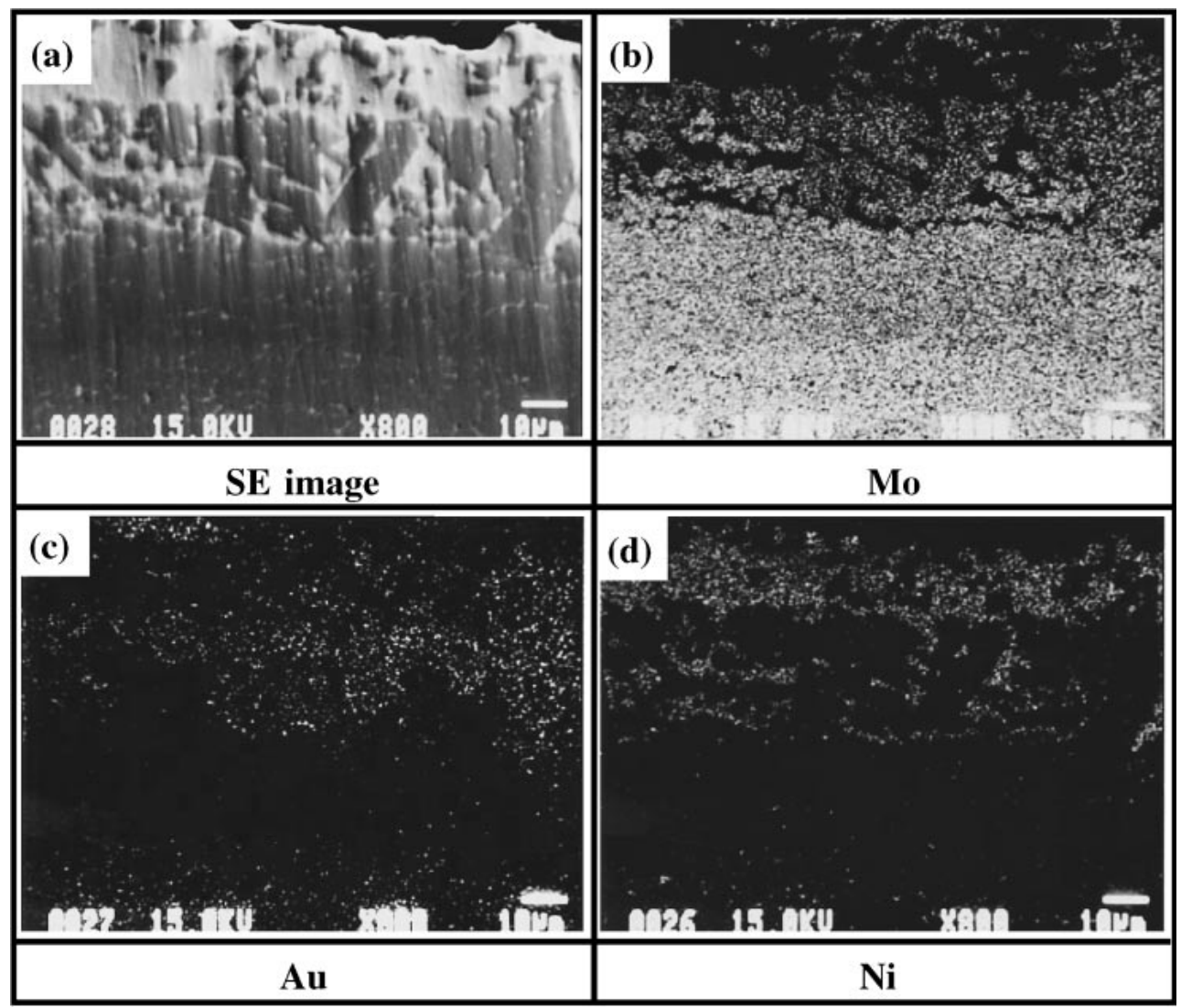

Fig. 4 EPMA plane analysis results of the cross section of $\mathrm{Mo} / \mathrm{Au}-18 \mathrm{Ni}$ interface brazed at $950^{\circ} \mathrm{C}$ for $30 \mathrm{~min}$.; $\mathrm{SE}$ image (a) and $\mathrm{Mo}$ (b), $\mathrm{Au}$ (c) and Ni (d) images of (a). 


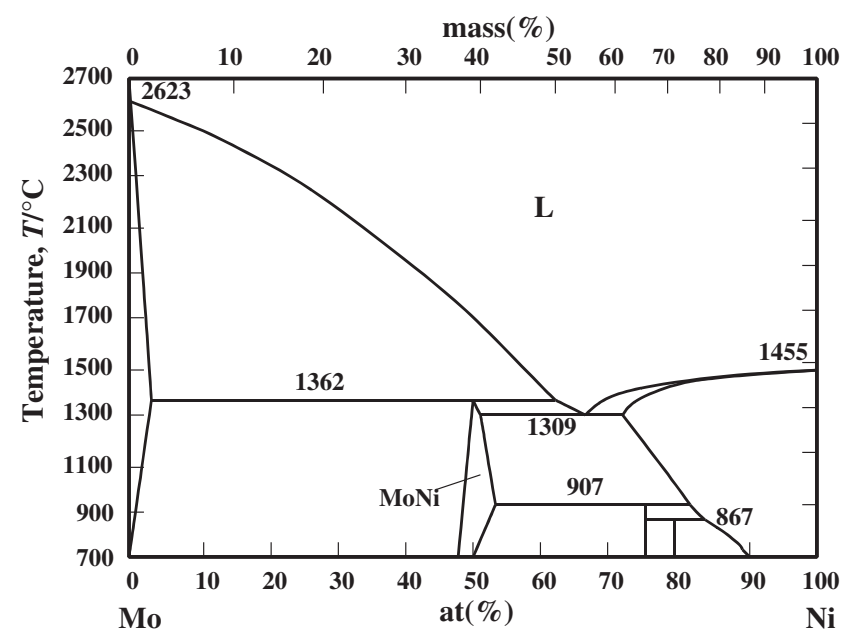

Fig. 5 Mo-Ni phase diagram. ${ }^{3)}$

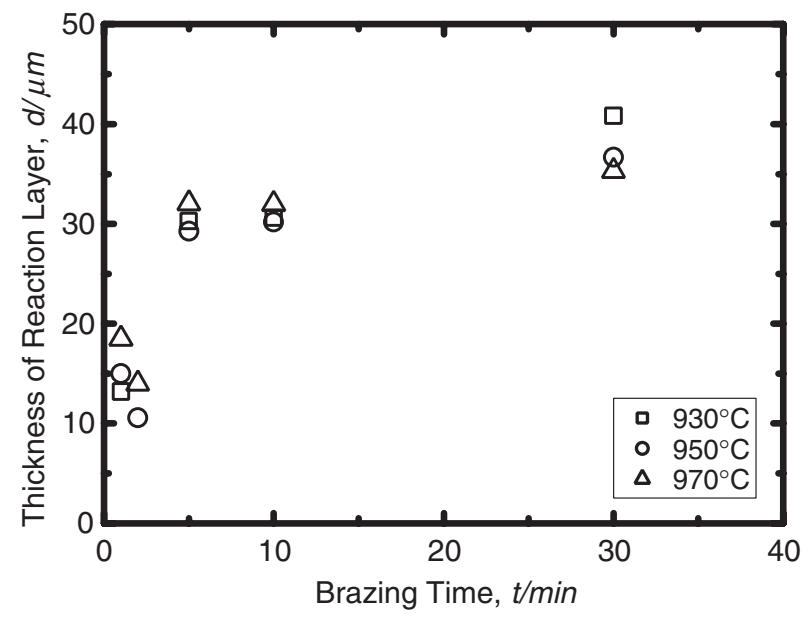

Fig. 6 Relationship between thickness of reaction layer and brazing time.

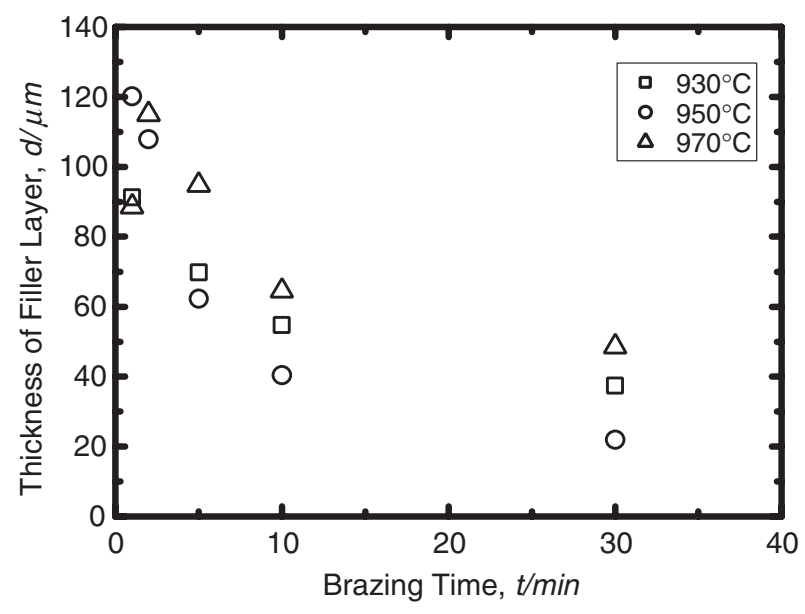

Fig. 7 Relationship between thickness of filler layer and brazing time.
Table 1 Vickers hardness measurement results.

\begin{tabular}{lc}
\hline Measurement Area & Vickers hardness $(\mathrm{Hv})$ \\
\hline Mo & 205 \\
MoNi & 682 \\
$\mathrm{Au}-18 \mathrm{Ni}$ filler & 182 \\
Mo+Au lamellar & 232 \\
\hline
\end{tabular}

\subsection{Vickers hardness of reaction layers}

Table 1 summarizes the results of Vickers hardness measurement. The hardness of MoNi formed at the brazed interface is very high and is 3.3 and 3.7 times those of Mo and the $\mathrm{Au}-18 \mathrm{Ni}$ filler layer, respectively. Usually, the Mo heater chip is subjected to a thermal cycle in the temperature range between R.T. and approximately $500^{\circ} \mathrm{C}$ under practical conditions. Therefore, it is undesirable to have such extremely hard phases in the brazed joint because they can cause cracks under thermal conditions. Thus, the brazing time must be controlled to a few minutes to prevent the excess growth of MoNi phases (refer to Fig. 6). Although the Vickers hardness of the Au-Mo lamellar layer is slightly higher than that of Mo, that is approximately one-third that of MoNi.

\section{Conclusions}

In this work, the microstructures and hardness of Mo brazed with $\mathrm{Au}-18 \mathrm{Ni}$ were investigated as the treatment method prior to bonding the thermocouple on the Mo heater chip.

(1) Spherical MoNi phases form initially at the brazed interface during brazing.

(2) With increasing the brazing time, a reaction layer with MoNi phases grows, and spherical MoNi phases change to columnar phases.

(3) $\mathrm{Au}$ atoms diffuse into Mo, and a microstructure of laminated $\mathrm{Au}$ and Mo forms in the Mo layer adjacent to the brazed interface.

(4) Vickers hardness of the MoNi phase is very high, which is approximately three and four times those of Mo and the Au-18Ni filler, respectively.

(5) The brazing time must be controlled to less than a few minutes in order to prevent excess growth of the reaction layer with MoNi.

\section{REFERENCES}

1) H. Yamamoto: The Journal of Japan Institute for Interconnecting and Packaging Electronic Circuits 12 (1997) 353-356.

2) H. Maki, O. Takahashi and S. Sekiguchi: Journal of Japan Institute of Electronics Packaging 2 (2000) 98-102.

3) H. Okamoto: Phase Diagrams for Binary Alloys, (ASM International, $2000)$ pp. 572.

4) H. Okamoto: Phase Diagrams for Binary Alloys, (ASM International, 2000) pp. 79. 